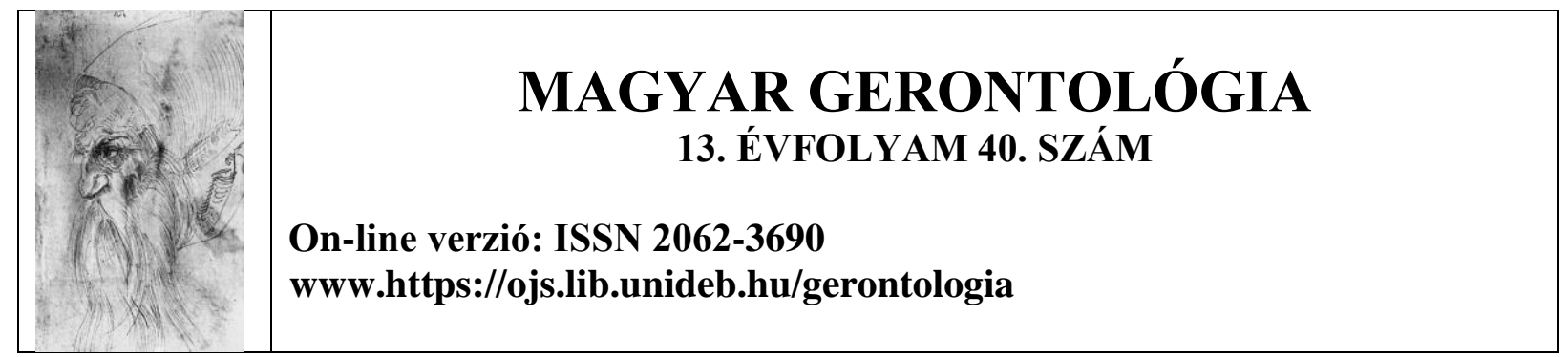

\title{
AN EXPLORATORY METAPHOR ANALYSIS ON THE PERCEPTIONS OF NURSING STUDENTS ABOUT THE CONCEPT OF AGING
}

\author{
Emel Bahadir Yilmaz*, Arzu Yüksel** \\ * Giresun University, Faculty of Health Sciences, Department of Nursing, Turkey \\ ** Aksaray University, Faculty of Health Sciences, Department of Nursing, Turkey
}

Keywords: Nursing, student, aging, metaphor

\begin{abstract}
Purpose: The aim of this study was to reveal the perceptions of nursing students about the concept of aging through metaphors.

Methods: The basic qualitative research design was used to evaluate the metaphors of nursing students regarding the concept of aging from their perspectives. The study sample consisted of 104 senior nursing students at Aksaray University in the 2021-2022 academic year. A purposive sampling method was used. "Metaphoric Perceptions Data Collection Form", which was prepared by the researchers in line with the literature, was used as a data collection tool. The form consists of two parts. In the first part, the demographic characteristics of the students were investigated. In the second part, the sentence "Aging is like ... because ..." was given to reveal students' metaphors regarding the concept of aging. The metaphors developed by the students regarding the concept of old age were analyzed and interpreted with Metaphor Analysis. Metaphor analysis has been associated with content analysis.

Results: The mean age of the students participating in the study was $21.65 \pm 0.99$ (min: 20, max: 25). Of students, $68.6 \%$ were female, $33.3 \%$ lived in city, and $84.3 \%$ had nuclear family. About
\end{abstract}


half $(50.0 \%)$ of their grandparents lived in their house. Of the students, 39.2\% thought about living with your parents when you start a family in the future; $52.9 \%$ lived with older adults aged 65 and over until now; $92.2 \%$ cared for an older patient during clinical practice; and $74.5 \%$ wanted to work in a health institution serving the elderly after graduation. Students produced a total of 102 valid metaphors for the concept of aging. Four main themes were obtained from the data. The main themes were aging as an ending story, a need for care, attention, and support, a new beginning, and a source of life.

Conclusion: Nursing students' metaphors about aging are generally negative, but also contain expressions of respect.

\section{Introduction}

The aging period, an essential stage in human life, is included in social and health science study areas. Today's nursing students will form professionals who provide services to the elderly in society soon. Compared to other community segments, the geriatric age group has a higher need for permanent care. Considering these features, it is a crucial issue to know students' attitudes in the field of health towards the elderly (Salman et al., 2018).

Studies using the Ageism Attitude Scale in Turkey show that the attitudes of nursing students are not discriminatory (Bahadır-Yılmaz, 2018; Yardımcı-Gürel, 2019). However, studies evaluating students' attitudes by asking open-ended questions show that they do not have the desired attitudes. After graduation, a low percentage of students want to work with the elderly group (3.9\%), and they perceive old age as more "compassion, wisdom, dependency" (Salman et al., 2018). In another study, $36.3 \%$ of students expressed a willingness to care for older people in the future (Ayaz-Alkaya \& Birimoğlu-Okuyan, 2017). According to another study, a low percentage of students $(4.2 \%)$ want to work with the elderly group after graduation, and most (69.8\%) perceive aging as "dependence, passivity, poverty" (Adıbelli et al., 2013).

Some factors affect students' attitudes towards aging. Students who live with the older adult at home, care for elderly family members and communicate with elderly individuals every day have higher attitude scores towards aging (Ayaz-Alkaya \& Birimoğlu-Okuyan, 2017). Students who are senior students, female, who live with the older adult at home, and care for elderly family members have higher attitude scores towards aging (Altay \& Aydın, 2015). These results show that students who interact with an older adult have more positive attitudes.

The rate of students taking gerontology nursing course in undergraduate education is very low. Only $22.3 \%$ consider the training received to be sufficient to meet the care needs of a geriatric patient (Adibelli et al., 2013). Therefore, some studies to increase and maintain a positive 
attitude towards the elderly recommend including more topics and practices related to aging and elderly care in undergraduate education, to ensure that students participate in activities that will increase awareness of elderly care, and to organize programs on geriatric nursing before and after graduation (Adıbelli et al., 2013; Ayaz-Alkaya \& Birimoğlu-Okuyan, 2017).

\section{Aim}

This study aimed to reveal the perceptions of nursing students about the concept of aging through metaphors.

\section{Methods}

Design

In the research, from the qualitative research designs (Merriam, 2013) focusing on how individuals create, interpret, and add meaning to their lives, the phenomenological (phenomenological) design, which is used to determine the opinions of individuals about a phenomenon, was used. The phenomenology design focuses on phenomena that are aware of but do not have an in-depth and detailed understanding (Yıldırım \& Şimşek, 2008). In the study, the basic qualitative research design was used to evaluate the metaphors of nursing students regarding the concept of aging from their perspectives.

\section{Participants}

The study sample consisted of 104 senior nursing students at Aksaray University in the 20212022 academic year. A purposive sampling method was used. These participants were preferred in the sampling with the criterion of easy accessibility. One hundred four students agreed to participate in the study in the data collection phase.

\section{Data collection tools}

The research data were collected with metaphors, which is a frequently used data collection method to describe and understand experiences and perceptions. The purpose of collecting data with metaphors is to obtain in-depth information about how individuals perceive events through the metaphors obtained through interviews and the meanings attributed to the metaphors (Yıldırım \& Şimşek, 2008). In the study, "Metaphoric Perceptions Data Collection Form", which was prepared by the researchers in line with the literature, was used as a data collection tool. The form consists of two parts. In the first part, the demographic characteristics of the students were investigated. In the second part, the sentence "Aging is like ... because ..." was 
given to reveal students' metaphors regarding the concept of aging. The participants were given a metaphorical perceptions data collection form, and they were asked to fill in the forms by creating a single metaphor in line with their thoughts on the concept of aging. No guidance was given to them in this context.

In addition, the form used as a data collection tool included information about the purpose of the research, the purpose for which the obtained data will be used, and the concept of metaphor. Students were given 20 minutes to think about the concept of old age sufficiently and to produce their metaphors for this concept. These forms, which the students filled in with their handwriting, constituted the main data source of the research.

\section{Ethical considerations}

Ethics committee approval was obtained from the Aksaray University Faculty of Medicine Clinical Research Ethics Committee and written permission from the institution where the study would be conducted before the study was conducted. In addition, the students who accepted to participate in the research were informed about the researchers' purpose and method of the study, and their written and verbal consents were obtained.

\section{Data analysis}

The metaphors developed by the students regarding the concept of old age were analyzed and interpreted with Metaphor Analysis (Cameron \& Low, 1999; Bryant \& Charmaz, 2007; Cameron \& Maslen, 2010; Suter, 2012). Metaphor analysis has been associated with content analysis (Moser, 2000). It was conducted by Saban (2009) in 5 stages. The data analysis in this study was carried out in five stages:

(1) Coding and sorting phase: It was checked whether there was a specific metaphor in the students' writings. Coding was done according to the metaphors produced. The codes were delivered as both words and phrases. Codes made in the form of words or phrases are "turtle," "growing tree," "last page of the book," "tree that has shed its leaves."

(2) Sample metaphor image compilation phase: This time, the metaphors put forward by the students were arranged in alphabetical order, and the raw data were reviewed again. A "sample metaphor list" was created by choosing one "example metaphor expression" representing each metaphor.

(3) Main theme and sub-themes development phase: At this stage, useful metaphors were examined in terms of their common features. The subject of the metaphor was analyzed in terms of the source of the metaphor and the relationship between the subject and the source of the 
metaphor. Each metaphor image has been associated with a theme in terms of common features related to aging, examined under different conceptual main themes, and divided into subthemes.

(4) The stage of ensuring validity and reliability: It is essential to present the research process in detail to ensure validity in qualitative research. For this reason, the analysis of the data is explained in detail. During the data analysis, the sample metaphor image was compiled, the compiled sample metaphor image was included in the findings section, and quotations were made from the students' statements. In order to ensure the reliability of the research, the metaphor, main theme, and sub-themes were finalized in line with the expert opinions taken by taking expert opinions from 3 faculty members who are experts in their fields.

(5) Transferring the data to the computer environment: At this stage, the frequency (f) values were calculated by transferring the metaphors, main themes and sub-themes to the computer environment.

\section{Results}

\section{Sociodemographic characteristics}

The mean age of the students participating in the study was $21.65 \pm 0.99$ (min: 20, max: 25). Of students, $68.6 \%$ were female, $33.3 \%$ lived in city, $84.3 \%$ had nuclear family, and $82.4 \%$ perceived moderate socioeconomic status. Of them, $70.5 \%$ perceived good family relationships and $93.1 \%$ of their parents lived together. About half $(50.0 \%)$ of their grandparents lived in their house. Of the students, 39.2\% thought about living with your parents when you start a family in the future; $52.9 \%$ lived with older adults aged 65 and over until now; $92.2 \%$ cared for an older patient during clinical practice; and $74.5 \%$ wanted to work in a health institution serving the elderly after graduation (Table 1 ).

Table 1. Students' sociodemographic characteristics $(\mathbf{n}=102)$

\begin{tabular}{|l|l|l|l|}
\hline Characteristics & $\mathrm{n}$ & $\%$ \\
\hline \multirow{3}{*}{ Gender } & Female & 70 & 68.6 \\
\cline { 2 - 4 } & Male & 32 & 31.4 \\
\hline \multirow{3}{*}{$\begin{array}{l}\text { Age } \\
\text { mean } \pm \mathrm{sd}=21.65 \pm 0.99)\end{array}$} & 20 years old & 6 & 5.9 \\
\cline { 2 - 4 } & 21 years old & 47 & 46.1 \\
\cline { 2 - 4 } & 22 years old & 32 & 31.4 \\
\cline { 2 - 4 } & 23 years old & 14 & 13.7 \\
\cline { 2 - 4 } & 25 years old & 3 & 2.9 \\
\hline \multirow{3}{*}{ Place of residence } & Metropolitan city & 23 & 22.5 \\
\cline { 2 - 4 } & City & 34 & 33.3 \\
\cline { 2 - 4 } & Town & 30 & 29.4 \\
\hline
\end{tabular}




\begin{tabular}{|c|c|c|c|}
\hline & Village & 15 & 14.8 \\
\hline \multirow[t]{3}{*}{ Family structure } & Nuclear & 86 & 84.3 \\
\hline & Extended & 11 & 10.8 \\
\hline & Divorced & 5 & 4.9 \\
\hline \multirow{3}{*}{$\begin{array}{l}\text { Perceived socioeconomic } \\
\text { status }\end{array}$} & High & 9 & 8.8 \\
\hline & Moderate & 84 & 82.4 \\
\hline & Low & 9 & 8.8 \\
\hline \multirow[t]{3}{*}{ Parents' relationship status } & They live together & 95 & 93.1 \\
\hline & They live apart & 5 & 4.9 \\
\hline & Father is not alive & 2 & 2.0 \\
\hline \multirow[t]{3}{*}{ Perceived family relationships } & Good & 72 & 70.5 \\
\hline & Medium & 28 & 27.5 \\
\hline & Bad & 2 & 2.0 \\
\hline \multirow[t]{4}{*}{ Where grandparents live } & They are not alive & 23 & 22.5 \\
\hline & They live in their house & 51 & 50.0 \\
\hline & $\begin{array}{l}\text { They live with their first- } \\
\text { degree relatives }\end{array}$ & 16 & 15.7 \\
\hline & $\begin{array}{l}\text { They live with the } \\
\text { students' families }\end{array}$ & 12 & 11.8 \\
\hline \multirow{2}{*}{$\begin{array}{l}\text { Thinking about living with } \\
\text { your parents when you start a } \\
\text { family in the future }\end{array}$} & Yes & 40 & 39.2 \\
\hline & No & 62 & 60.8 \\
\hline \multirow{2}{*}{$\begin{array}{l}\text { Living with older adults aged } \\
65 \text { and over until now }\end{array}$} & Yes & 54 & 52.9 \\
\hline & No & 48 & 47.1 \\
\hline \multirow{2}{*}{$\begin{array}{l}\text { Caring for an older patient } \\
\text { during clinical practice }\end{array}$} & Yes & 94 & 92.2 \\
\hline & No & 8 & 7.8 \\
\hline \multirow{2}{*}{$\begin{array}{l}\text { Wanting to work in a health } \\
\text { institution serving the elderly } \\
\text { after graduation }\end{array}$} & Yes & 76 & 74.5 \\
\hline & No & 26 & 25.5 \\
\hline
\end{tabular}

\section{Themes}

Students produced a total of 102 valid metaphors for the concept of aging. The metaphors revealed the students' perceptions of the concept of aging. Four main themes and 11 sub-themes were collected. The main themes were aging as an ending story, a need for care, attention, and support, a new beginning, and a source of life. Sub-themes were acceptance, no turning back, approaching the end, deprivation, helplessness, being dependent, rooting, starting, guiding, being a building block, and being valued (Figure 1). 


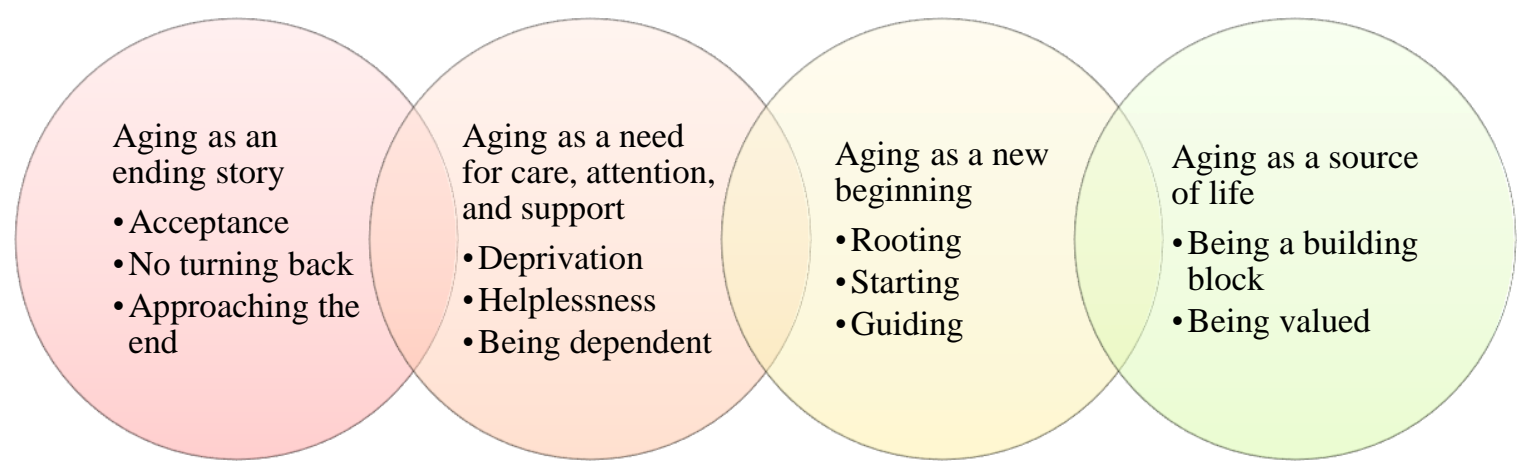

Theme 1. Aging as an ending story

\section{Acceptance}

In this sub-theme, students interpreted aging as irresistible.

"Aging is living alone, loneliness; because they don't want it as they get older." (S.15)

"Aging is like fatigue; because physical strength decreases and health deteriorates." (S. 23)

"Aging is mostly helplessness when you have no one; it is the state of a child, it is a way of expressing what you have lived until that age; because you don't have anyone, you can't do anything when you're sick." (S. 47)

No turning back

The prominent feature of the metaphors in this sub-theme was that old age had a disability.

"Aging is like my outgoing dreams; because my dreams are dead like old people." (S. 6)

"Aging is like a child whose toy has been taken away; because old people lost many things he had and their abilities.” (S. 66)

"Aging is like a chronic disease; because old people need special care after a while, and a person with a chronic disease also needs special care.” (S. 72)

\section{Approaching the end}

In this sub-theme, students saw aging as death and an end. 
"Aging is like autumn; because you see a tree in its most magnificent state in spring; then autumn comes, only a dry wood remains from that magnificent tree.”(S. 12)

"Aging is like the last page of the book; because the life of a person is like the leaves of a book, people are born, and the book begins, the pages of the book progress as people live, and at the end of aging, people have come towards the end of their life."(S. 73)

"Aging is like the last journey; because they have gone on many difficult journeys in their lives, and aging is the last stage of this journey. They will make their preparations and go on a journey for the last time. Some will continue to explore new places on this journey. Some will rest and sleep on this journey. And they will complete their journey."(S. 85)

Theme 2. Aging as a need for care, attention, and support

\section{Deprivation}

"Aging is like a tree that has lost its leaves; because he has come to the end of his life." (S. 22)

"The value of aging is unknown, similar to an item that becomes valuable when one dies; because it is considered useless." (S. 61)

"Aging looks like a tree devoid of branches; because as they get older, their children start to leave one by one." (S. 79)

"Aging is like a pencil; because as it functions, moves, and is used, it is consumed and eventually ends." (S. 86)

\section{Helplessness}

"Aging is like a turtle; because you live life slower than others." (S. 62)

"Aging is like an open wound; because when we don't take care of it, it opens even more, and eventually a bad result occurs." (S. 67)

"Aging is like the decay of a fruit after it has ripened; because human life has a developmental stage, a maturity, and a death, that is, an end." (S. 76)

\section{Being dependent}

"Aging is like childhood; because children are dependent on someone else for both love and care." (S. 2)

"Aging is like a newborn baby; because they require care." (S. 4)

"Aging is like a flower that withers and demands care; because all of their systems have regressed, and they are unable to meet their daily needs.” (S. 44)

"Aging is like childhood; because as they get older, people start to be like children, they become more fragile, they want attention, they need care, and they need help from someone" (S. 50) 


\section{Theme 3. Aging as a new beginning}

The prominent feature of the metaphors in this main theme is that aging is strong.

\section{Rooting}

In this sub-theme, students defined aging as a tree, plane tree, and rooted tree.

"Aging is like a tree; because it grows and takes root over the years." (S. 13)

"Aging is like a plane tree; because they have completed the rush of life, they gather his grandchildren and his family together as he sits in the shade of the plane tree." (S. 59)

"Aging seems to me like a big tree with long branches and a broad trunk; because they show us to be strong, to stand up despite everything, to hold on to life." (S. 77)

"Aging is like the earth; because we can get efficiency no matter how much it wears out." (S. 81)

Starting

"Aging is like heaven; because it is a beautiful thing." (S. 9)

"Aging is like a new world; because life for them has just begun." (S. 39)

"Aging is like climbing a mountain; because as you climb, your fatigue increases, your breath becomes narrower, but your vision expands." (S. 100)

\section{Guiding}

In this sub-theme, students defined aging as experience, library, and hope.

"Aging is like a library; because they have knowledge and experience about life, events and situations. We can find the answers we seek in them.” (S. 3)

"Aging is like experience; because older people are the most experienced." (S. 11)

"Aging is like an encyclopedia; because it is full of knowledge and experience." (S. 63)

"Aging is like a book; because it is worn out from use, but it is full of knowledge." (S. 80)

\section{Theme 4. Aging as a source of life}

\section{Being a building block}

In this sub-theme, students interpreted the concept of old age as maturation.

"Aging is like a fruit ripening with time; because the older you get, the more you enjoy life." (S. 28)

"Aging is like a ripe fruit; because, like fruits, people have a certain lifespan and become more and more mature as time goes on." (S. 29)

"Aging is a door to a new universe; because without a certain age we cannot acquire different thoughts." (S. 53) 


\section{Being valued}

"Aging is like aged wine; because over the years, each experience adds wisdom to one's soul." (S. 5)

"Aging is like a treasure chest; because it contains many treasures and experiences." (S. 60)

\section{Discussion}

The present study found four main themes and eleven sub-themes. The main themes were aging as an ending story, a need for care, attention, and support, a new beginning, and a source of life. Sub-themes were acceptance, no turning back, approaching the end, deprivation, helplessness, being dependent, rooting, starting, guiding, building blocks, and being valued. Two main themes projected positive attitudes towards aging, and two projected negative attitudes. Similarly, in a study, Turkish nursing students reported that they perceived aging more as "compassion, wisdom, addiction" (Salman et al., 2018). In another study, Turkish nursing students defined aging as “dependence, passivity, and poverty" (Adibelli et al., 2013). Özdil et al. (2021) found that Turkish nursing students' attitudes toward the elderly were positive. During the pandemic, their views of the elderly were vulnerable and emotional shake such as desolateness, exhaustion, feeling useless, and fear of death. However, Finnish nursing students considered older adults as individuals with their personalities and many resources (Salin et al., 2020). Some Thai nursing students defined the positive aspects of ageing, and older adults being wise, resourceful, and competent. Other described older adults as frail and in need of care and support (Mattsson \& Rosendahl, 2017).

Students' negative perceptions or attitudes towards aging may also negatively affect their willingness to work with the elderly. About - a little bit less than - two-thirds (58.0\%) of Turkish nursing students were willing to work with the old after graduation (Demir et al., 2016). According to a scoping review, nursing students in lower and middle-income countries reported insufficient knowledge in the care of older adults. However, nursing students reported positive attitudes towards the care of older adults but held misconceptions about caring for older adults. Nursing students also said a low preference for working with older adults (Abudu-Birresborn et al., 2019).

It is essential to present clinical experiences that will enable their interaction in developing students' attitudes towards older adults. Lack of experience with older adults caused a lack of enjoyment to work with them. After clinical experience in residential aged care, nursing students built positive relationships with older adults (Moquin et al., 2018). In addition, it is essential for instructors to be role models in developing positive attitudes towards older adults. 
In a study, because of instructors being positive and strong role models through demonstrations, expectations, and support, students mirrored their positive attitudes towards older adults (Gibbs \& Kulig, 2017). Finally, it is thought that receiving a gerontology nursing education will positively affect students' attitudes. Likewise, the education received about the elderly has increased physical, cognitive, and mental expectations of the students regarding old age (Akpınar-Söylemez et al., 2018).

\section{Conclusion and suggestions}

In conclusion, this study found that some students have positive attitudes towards older adults, and some have negative attitudes. In this direction, the following are recommended: 1) The interaction between students and older adults should be increased. 2) Students should take courses on aging and elderly care. 3) Students should receive clinical training in services or institutions with older adults.

\section{References}

Abudu-Birresborn, D., McCleary, L., Puts, M., Yakong, V., \& Cranley, L. (2019). Preparing nurses and nursing students to care for older adults in lower and middle-income countries: A scoping review. International Journal of Nursing Studies, 92, 121-134.

Adıbelli, D., Türkoğlu, N., \& Kılıç, D. (2013). Views of nursing students about ageing and their attitudes toward older people. Dokuz Eylül Üniversitesi Hemşirelik Yüksekokulu Elektronik Dergisi, 6, 2-8.

Akpınar-Söylemez, B., Akyol, M. A., Küçükgüçlü, Ö., \& Iş1k, A. T. (2018). Nursing students’ expectations regarding aging. Geriatrik Bilimler Dergisi, 1, 40-48.

Altay, B., \& Aydın, T. (2015). Evaluation of the attitudes of nursing students towards ageism. Hemşirelikte Ĕgitim ve Araştırma Dergisi, 12, 11-18.

Ayaz-Alkaya, S., \& Birimoğlu-Okuyan, C. (2017). Nursing students' attitudes towards the elderly. Hacettepe Üniversitesi Hemşirelik Fakültesi Dergisi, 4, 43-52.

Bahadir-Yilmaz, E. (2018). The relationship between nursing students' professional values and their attitudes towards the elderly people: A cross-sectional study. Nurse Education Today, 70, 8-12 
Demir, G., Biçer, S., Bulucu-Böyüksoy, G. D., \& Özen, B. (2016). Attitudes of nursing students about ageism and the related factors. International Journal of Caring Sciences, 9, 900908.

Gibbs, S. S., \& Kulig, J. C. (2017). "We definitely are role models": Exploring how clinical instructors' influence nursing students' attitudes towards older adults. Nurse Education in Practice, 26, 74-81.

Mattsson, K., \& Rosendahl, S. P. (2017). Teaching gerontology in globalized academics: a qualitative study of Thai nursing students' views on ageing when studying abroad. Contemporary Nurse, 53, 36-47.

Merriam, S. B. (2013). Qualitative research: a guide to design and practice (Turan S, Translation editor). Ankara: Nobel Academic Publishing.

Moquin, H., Seneviratne, C., \& Venturato, L. (2018). From apprehension to advocacy: a qualitative study of undergraduate nursing student experience in clinical placement in residential aged care. BMC Nursing, 17,8 .

Özdil, K., Küçük-Öztürk, G., Çatıker, A., \& Bulucu-Büyüksoy, G. D. (2021). Views of senior nursing students on the problems of the elderly during the Covid-19 process and attitudes against ageism. Dokuz Eylül Üniversitesi Hemşirelik Fakültesi Elektronik Dergisi, 14, 357-369.

Salin, S., Hautsalo, K., Vanni, K., Seitsamo, S., \& Yli-Koivisto, L. (2020). Finnish nurse students' attitudes towards older adults and the teaching of gerontological nursing - A survey study. Nurse Education Today, 88, 104379.

Salman, M., Gülçek, E., Aylaz, R., \& Polat, F. (2018). Evaluation of the attitudes of nursing students towards elderly people. Elderly Issues Research Journal, 11, 1-7.

Yardımci-Gürel, T. (2019). Attitudes of nursing students towards ageism and related factors. Turkiye Klinikleri Journal of Nursing Science, 11, 381-389.

Yıldırım, A., \& Şimşek, H. (2008). Qualitative research methods in the social sciences. Ankara: Seçkin Publishing. 


\section{The Authors:}

\section{Assoc. Prof. Emel BAHADIR YILMAZ*, Assoc. Prof. Arzu YÜKSEL**}

* Giresun University, Faculty of Health Sciences, Department of Nursing, Turkey. ORCID ID: 0000-0003-1785-3539

** Aksaray University, Faculty of Health Sciences, Department of Nursing, Turkey. ORCID ID: 0000-0001-7819-2020

\section{Corresponding Author:}

Dr. Emel BAHADIR YILMAZ, Giresun University, Faculty of Health Sciences, Department of Nursing, Piraziz, Giresun, Turkey.

E-mail: ebahadiryilmaz@yahoo.com.

Phone: +904543101840/3008 